\title{
OBRA E MANIFESTO: O DESAFIO ESTÉTICO DO TRABALHADOR DA SAÚDE.
}

WORK AND MANIFEST: THE AESTHETIC CHALLENGE OF HEALTH WORIKER.

Flávia Regina Souza Ramos ${ }^{1}$

RESUMO: $O$ artigo aborda a estética do trabalho em saúde, entendida a estética como relação fundamental do homem com o mundo e, portanto, modo de acontecer do sujeito em qualquer prática. Analisa o espaço de expressão estética do trabalhador da saúde, através de seu pensamento, ação e manifestação mais cotidianas, discute o objeto no marco sociológico e filosófico e apresenta algumas categorias geradas num processo pesquisa qualitativa. Recupera a relação tempo, espaço e sujeito, bem como a importância da imaginação e do simbólico na compreensão do trabalho em saúde, especialmente na perspectiva da relação trabalho e subjetividade e no resgate do desafio ético-estético do trabalhador - tornar o trabalho uma experiência de enunciação de si.

UNITERMOS: Trabalho em saúde - Trabalho e subjetividade - Filosofia e saúde.

\begin{abstract}
This work goal is the aesthetic of health work, aesthetic seen as the fundamental relation between Man and the world, thus the individual way of happening in any praxis. It analyses the space of aesthetic expression of health workers, through the most quotidian thought, action, and manifestation. It discusses the object in the sociological and philosophical landmark and presents some categories generated from a qualitative research process. It recovers time - space - subject relation as well as the importance of imagination and the symbolism in health work comprehension, especially on work and subjectivity relation and on worker ethical aesthetic deviation rescue - turn work into an experience of selfenunciation.
\end{abstract}

KEYWORDS: Work in health - Work and subjectivity - Philosophy and health.

'Enfermeira Doutora em Filosofia de Enfermagem - UFSC; Prof Adj. da UFMT

R. Bras. Enferm., Brasilia, v. 50, n. 3, p. 323-338, jul./set., 1997 


\section{FILOSOFIA, TRABALHO E SAÚDE: UMA INTRODUÇÃO AO PROBLEMA E SEUS MARCOS DE ANÁLISE}

Qual é a estética do trabalho em saúde? Que sujeito se revela no trabalho ou qual o espaço de expressão estética do trabalhador da saúde?

Esta foi a questão norteadora da pesquisa desenvolvida no Doutoramento em Filosofia de Enfermagem/UFSC, da qual algumas categorias e reflexões são tomadas neste artigo. Exatamente por propor um objeto novo no estudo do trabalho em saúde, algumas idéias de caráter fundamentador e demarcador do problema de pesquisa em si precisam ser discutidas com base em três possiveis marcos de análise: - o marco sociológico; - o marco do trabalho em saúde; - o marco filosófico-estético. Entende-se que só pela articulação destes conhecimentos pode-se aprofundar as questões que envolvem hoje a temática da existência concreta e subjetiva do trabalhador da saúde.

A globalização do processo de acumulação, fruto do moderno sistema capitalista mundial, gerou transformações econômicas importantes, com efeitos diretos sobre a organização do trabalho e a dinâmica do mercado de trabalho. Estas mutações sociais, econômicas e tecnológicas do Trabalho incidem radicalmente sobre o que se convencionou como a "identidade do trabalhador moderno". Ao nivel desta identidade não se pode negar que "o trabalho assalariado, como modelo de criatividade física e intelectual, está sofrendo um conjunto de reestruturações, que se traduzem na desagregação progressiva dos processos de identificação psicossocial do trabalhador para com seu trabalho" ${ }^{7}$.

Os virtuais beneficios do avanço tecnológico, por sua vez, não possuem uma linear e automática ressonância na vida concreta dos trabalhadores. Entre o modo como determinado trabalho visivelmente se mostra hoje e a tecnologia operante, se estabelece uma complexa rede de mediações, continuidades e descontinuidades de caráter histórico-econômico que se articulam a toda uma racionalidade científica e uma dada organização social. Isto envolve a negação de qualquer neutralidade do saber e dinâmica tecnológica.

A formação do sujeito pela via do trabalho é um dos aspectos que envolvem a estética do trabalho, já que a estética, em sua relação com o trabalho, pode ser considerada por uma dupla via, a do trabalho que forma o sujeito e a do sujeito que forma o trabalho. Em outras palavras, a relação estética do homem com o processo mesmo em que se torna "trabalhador" (que inclui a relação com objetos e meios de trabalho, outros homens, consigo mesmo e, virtualmente, com a sociedade como um todo) não apenas the oferece experiências $e$ percepções que, ao serem consumidas esteticamente, influem na sua subjetividade ou forma de se colocar no mundo (a criação do homem no trabalho), como também, este mesmo trabalho será o terreno das manifestações deste sujeito e, portanto, recriado por ele. 
Então, captar a estética deste trabalho humano é captar o que existe de humano neste trabalho, e a busca de tal apreensão passa, necessariamente, pela leitura das transformações que se anunciam neste cenário.

A contribuição deste tipo de análise reside na discussão do novo local destinado ao trabalho na sociedade atual (ou quem sabe na sociedade por vir), do valor dado ao trabalhador e ao produto de seu trabalho. Em suma, discute novas possibilidades de relação entre o agir humano, sua obra e o usufruto destas obras. Daí se origina sua principal implicação, a abertura para o estabelecimento de uma nova utopia do trabalho.

Se hoje o trabalho produtivo perde sua centralidade subjetiva e histórica, sua crítica deve transcender suas manifestações tangiveis e constituir-se em possibilidade de emancipação crítica do trabalho social. Deve reconhecer a heterogeneidade dos sujeitos e de aberturas dentro e fora do trabalho. As condições deste novo trabalho estão ligadas também ao processo de trabalho concreto, mesmo sendo ele restrito e parcelar. Mesmo em face da construção de novos espaços de realização do sujeito, a crítica ao trabalho não deve ser menosprezada. A prática e sua compreensão são os pilares desta emancipação.

Tendo como referência a recente produção cientifica sobre o processo de trabalho em saúde, diversos desafios podem ser levantados, descortinando novas perspectivas no tratamento do processo de trabalho. Eles se referem:

A) - À necessidade de captar a realidade da existência social dos recursos humanos no interior das práticas de saúde, relativizando tanto sua autonomia de sujeito profissional quanto as determinações sociais que pesam sobre seu trabalho ${ }^{14}$.

B) - Ao papel que o domínio da técnica representa para o trabalhador que, vendo negadas outras possibilidades de exercício de autonomia, passa a configurar este domínio como fim último de seu trabalho, ocupando mesmo o vazio deixado pela "impossibilidade" de contestação do próprio modelo tecnológico que o conforma e pela sua distância em relação a um projeto político para este trabalho e para a saúde coletiva como um todo.

C) - À importância das representações, idealizações e mistificações envolvendo o próprio trabalho para a compreensão da dinâmica deste trabalho na sociedade, de sua racionalidade e dos descompassos entre o vivido e o imaginado.

D) - Aos conflitos vividos por estes trabalhadores ao se depararem com necessidades de intervenções sobre carências humanas múltiplas e complexas; com um um trabalho cooperativo com grandes deficiências teóricas, organizativas e operacionais; com a falta de clareza sobre seu próprio objeto, finalidades de trabalho e uso de instrumentos nem sempre adequados aos fins almejados. 
Enfim, o conflito entre o que the cabe enquanto dever e compromisso - a face visivel do trabalhador - e o que lhe cabe enquanto homem que constrói e "reclama por existir humanamente" - a invisivel face do sujeito. Visivel e invisivel que se expressam e se escondem, transparecem e já se refazem.

Frente a estas considerações é que se apresenta destacadamente a preocupação em reconhecer o espaço de realização da subjetividade deste trabalhador no exercicio concreto de seu trabalho, o que, aliás, denota a preocupação estética. Reconhecer as bases materiais deste trabalho, mas também seus significados no âmbito da externalização do sujeito através daquilo que faz, emergência do sujeito através do domínio do saber em ato e da razão sensivel e criadora.

Um outro argumento fundador deste problema de pesquisa pode ser apontado na relação de cumplicidade e entrelaçamento que a ética e a estética estabelecem entre si e, conseqüentemente, com uma das mais importantes questões da vida humana, o trabalho: Será que o desejo de criar, de negar o que é, e incessantemente querer ser e fazer diferente, eclode também, de algum modo e em algum momento, quando o trabalhador se debruça sobre seu fazer cotidiano e sem brilho? Seria só pelo espaço da música, poesia, pintura, permitido a poucos e nas horas "roubadas" do trabalho, que o homem comum teria a possibilidade de expressão de si e de construção de uma vida bela?

A estética pode desnudar o mais público e o mais privado dos espaços - o espaço das relações de um sujeito-trabalhador com outros sujeitos, trabalhadores e clientes; o espaço de resistência de um trabalhador que quer se pôr na sua ação, que quer se ver e se realizar naquilo que faz - o espaço do trabalho.

É esta estética que, por se voltar para o dia a dia "insignificante" e "desinteressante" (ao olhar de uma ciência arrogante), pode ser chamada de micro- estética ou estética do cotidiano. E ela pode ser pensada enquanto modo de se realizar qualquer prática individual ou coletiva... modo de acontecer do sujeito na prática.

O vir à tona no qual a sujeito se reconhece por si mesmo e através do outro: esta é a micro-estética a ser tomada como elemento de consciência e autoconstrução do trabalhador, ser humano concreto peculiar ${ }^{15}$.

A ética acompanha estas noções de arte e estética a partir do momento em que é tomada como "estética da existência, como horizonte que permite dar estilo à própria vida na relação consigo mesmo e com os outros, que permite "esculpir a si mesmo como obra de arte" ou "produzir-nos a nós mesmos como sujeitos morais de nossas próprias ações" ${ }^{2}$. E se o trabalho não é apenas processo de produção, mas também de autoprodução, o terreno da ética e do trabalho se fundem mesmo num marco onde exploração e desigualdade parecem excluir a estética da existência. Este é o desafio ético e estético ao qual o sujeito-trabalhador tem que responder com seu próprio trabalho. 


\section{OLHAR E IMAGINAÇÃO: PARA SE TECER A TRAMA DO REAL}

O homem não apenas percebe o real concreto, ele imagina, procede o ato formador de novos objetos, instaura universos, como se o componente racionalreal (que representa o real e define o pensamento-ação racional) fosse tecido inextricavelmente com o componente imaginário. A incessante troca entre real e imaginário se faz de modo estético, definida esta como uma relação humana fundamental, uma relação primária com o mundo.

Pode-se olhar para o trabalho como uma destas possibilidades de expressão do imaginário, como uma obra que secreta uma imaginação e, talvez até, uma mitologia e ritualística própria. Parafraseando Bachelard ", "toda atividade humana deseja falar".

Podemos pensar na participação estética de um trabalhador no exato momento em que executa sua obra; na relação estética que se opera quando este trabalhador contacta com esta obra e com o outro que está ao seu lado. $E$ na tradução desta estética do trabalhador com seu universo real e imaginário ganham fisionomia pelo menos três personagens: o eu, o outro e a instituição.

\section{A imagem de si e a imagem em si}

A experiência de ser, de perceber-se como existência sempre se faz na referência com o outro que se põe fora do limite do ser que se percebe. "EU" existo porque existe o "OUTRO" que não sou eu, como o aqui existe em relação a outro lugar e o agora existe em relação ao passado ou ao futuro. A imagem que o trabalhador constrói de si se faz em referência ao tempo vivido e lugar ocupado numa rede de outras existências, no cruzar de pessoas e coisas que continuamente ganham e perdem sentido para sua existência ${ }^{3}$.

Se o trabalho ocupa grande parte deste tempo e espaço vivido, é de se esperar que este imaginário, que se ocupa de lidar com a relação de si com o mundo, esteja irremediavelmente aderido às percepções e experiências que faz de si como trabalhador, ou que faz do mundo do seu trabalho. Neste momento, os trabalhadores parecem conseguir o impossivel: preservar "algo" que excede a "imagem de si", fortemente ligada ao seu fazer prático, como numa "imagem em si”.

\section{TRABALHADOR}

se identifica com o seu trabalho (identificação) ser/eu se faz e se reconhece no trabalho

se identifica em oposição ao seu trabalho (negação)--- O ser/eu se faz e se reconhece fora do trabalho 
Ocorrendo em uma relação de oposição ou de afirmação com o trabalho, este desempenha um relevante papel para o processo de reflexão sobre si mesmo. Uma das formas de se evidenciar isso é pela idéia que o sujeito faz de si enquanto trabalhador, ou melhor, pelo modo como fala do que denomino "estilo", o "jeito" de ser e fazer no/o trabalho; o que diferencia cada trabalhador entre tantos outros. Ao se referirem a este estilo/modo de ser e fazer, nota-se uma clara referência a certas qualidades ou predicados tidos como positivos e importantes. Como que checando suas qualidades com a de uma espécie de mito guiador imaginário, o trabalhador fala de si através dos atributos que reconhece em si.

Neste confronto com o mito guiador imaginário, estes trabalhadores desenvolvem suas próprias estratégias de negociação (negocia com seu mito, convencendo-se que aquilo que pode parecer indesejável é, em muitos momentos, louvável, eficiente e benéfico); resistência (resiste ao modelo de comportamento e competência institucionalmente hegemônico, reforçando seus valores ou uma postura racionalmente eleita); reformulação (mitos guiadores vão sendo reconstruídos pela experiência e pelo conhecimento de si e do outro. Isto vai, pouco a pouco, tomando o tempo e o espaço do "desempenhar o papel mitificado" pelo, cada vez maior tempo e espaço de "desempenhar o papel a que se permite" ou desempenhar-se como pessoa inteira).

Para empreender a crítica destes mitos é preciso, antes de mais nada, admitir que além da função de Evasão que estes conteúdos projetivos permitem em relação à insegurança, à ameaça e aos dramas e tragédias da vida social, eles possuem uma segunda e importante função: a de integração deste indivíduo (tal como é) à sua família, ao grupo, ao trabalho, à sociedade (tal como são). Como diz Rosset ${ }^{12}$, "nada mais frágil do que a faculdade humana de admitir a realidade, de aceitar sem reservas a imperiosa prerrogativa do real." Estes mitos fornecem as máscaras que possibilitam olhar para este real e para si mesmo, permitem o artifício de sedução. E se "seduzir é morrer como realidade e produzir-se como engano" ", nada mais humano do que a necessidade de seduzir e ser seduzido; seduzido pela vida e pela imagem que faz de si e do outro.

\section{A dialética da conformação}

Mas como se mostram, na concretude do fazer diário, estas nuanças tão subjetivas entre o sujeito que se vê naquilo que faz, ou que sente a possibilidade de manifestação autêntica e expressiva de si, e o sujeito que assume para si uma outra atividade, dando a si próprio um novo uso? Que processos subjetivos se desenvolvem neste sujeito, consciente ou não, nesta dialética do conformar o trabalho e por ele ser conformado? 
Os trabalhadores expressaram, em sua maioria, a nítida percepção da diferença entre momentos em que "se sente ele mesmo", "fazendo do seu jeito", e outros momentos em que age por assumir papéis, responsabilidades e condutas definidas e esperadas. O critério ou ponto de referência utilizado para esta diferenciação mistura conteúdos da razão e do sentimento e se estabelecem em torno de conflitos ou cisões básicas:

\begin{tabular}{|c|c|c|}
\hline "o que gosta de fazer" & $X$ & "o que não gosta de fazer" \\
\hline "o que sabe fazer" & $X$ & "o que não sabe fazer bem" \\
\hline "o que é fácil de fazer" & $X$ & "o que é dificil de fazer" \\
\hline "o que deseja fazer" & $X$ & "o que não deseja fazer" \\
\hline
\end{tabular}

Transparece, também, o quanto o processo de autoconhecimento permeia a experiência de tornar-se trabalhador e de buscar dignidade e satisfação no trabalho.

Nesse mesmo processo, no qual o trabalhador descobre potenciais e limites e fortifica suas ligações com o trabalho, inventando novos artifícios face aos enfrentamentos cotidianos, ele descobre, também, uma outra capacidade, a de adaptação e sacrifício. Os sacrifícios meio astuciosos, revestidos de banalidade, que tentam resolver uma certa tensão angustiante entre o real e o ideal, entre o querer e o dever. O que a primeira vista pode parecer uma fraqueza ou abandono do trabalhador às exigências do trabalho, pode, também, ser visto como mecanismo do trabalhador para, na ausência de identificação com grandes heróis e mitos salvadores, realizar do melhor modo possível e em si próprio, o que sente possível do seu ideal e modelo, do "alter ego" (outro eu) que precisa encontrar ressonância, precisa de alguém com quem se identificar, precisa de um mínimo espaço para se manifestar. Sacrifício não como oferenda ou castigo sagrado, mas como apelo a si mesmo, apaziguamento eficaz do eu com seu duplo, de uma imagem de si com seu fantasma ou sombra. Resistência frente a um risco bem maior: a perda do auto-referencial, da auto-estima, da identidade de trabalhador. Isto, na linguagem do trabalhador da saúde, possui várias denominações: responsabilidade, compromisso; necessidade.

\section{A Imagem além de si}

Os trabalhadores da saúde têm uma consciência de si fortemente imbricada no trabalho que realizam, que lhes toma grande parte da existência e da energia; e para onde acaba se dirigindo grande parte de suas pulsões psiquicas e emocionais. A imagem de si é arquitetada na relação que se estabelece com o outro e com o tempo/espaço vivido. Assim, falar de si é pouco. Falar de si é, irremediavelmente, falar além de si, do que está fora, mas participa da construção desta identidade em movimento: a instituição e o outro. 
O trabalhador da saúde se coloca num terreno pluri-institucional. Ao mediar a relação de um outro homem com seu desaparelhamento, fragilidade e submissão frente ao acontecimento da dor e da morte, medeia também a consciência do limite e fracasso do corpo, da ciência, da sociedade, de tudo que foi instituído como saber sobre a doença e como poder humano (tecnológico) sobre esta doença.

Do confronto com uma normatividade instituida e com os limites, visíveis ou não, que dai advêm, o trabalhador vai reconhecendo os obstáculos e restrições que de alguma forma reprimem seu expressar mais livre, disciplinam sua diversidade ao mesmo tempo que excluem laços de reciprocidade com o outro. Como estas limitações são compreendidas (até um certo ponto) e atribuídas a diferentes origens, a gênese institucional das restrições impostas ao trabalhador são evidenciadas quando relacionadas a instituições concretas, num discurso que inscreve a instituição na ordem da sujeição e inibição.

Já onde o limite é sentido como próprio de si (auto-repressão), ele parece investir ainda mais ofensivamente, porque o sujeito incorpora à sua identidade o atributo de sua formação/profissão, e sente como sua a opressão desta identidade profissional assumida.

\section{O outro: uma outra imagem no espelho}

Muitos dos "obstáculos" são associados a esta relação com o outro no território artificial do trabalho institucionalizado. Este "outro que me limita" pode ser "o outro-colega de trabalho" ou "o outro-paciente/cliente" a quem se destina o trabalho.

Quando se trata de outros trabalhadores, o sujeito parece olhar para este "outro" com o filtro de olhar que lança sobre si mesmo.. Os mitos guiadores que servem de condutores, vigilantes e legisladores de sua própria atuação serão agora também aplicados àquele outro que lhe divide o espaço, com uma relativa maior facilidade ou sem tantos mecanismos de autoproteção. Mas se esse outro não Ihe é tão estranho, pois há entre si alguma força aglutinadora de identificação e representação, uma margem segura de aceitação precisa ser preservada para garantir a sobrevivência de uma imagem necessária. A destruição "imaginária" da instituição e do "outro" seria a destruição de uma parte de si.

Nascida desta contradição entre solidariedade e rejeição, estranheza e similaridade, a fala do trabalhador mistura a compreensão de si e a compreensão do outro - aquele que "não sou eu", aquele que "me reflete, me representa e lembra minha própria diferença". O outro "tão longe e tão perto" precisa responder (como "eu respondo") pelos seus atos; precisa enfrentar (como "eu enfrento") o espelho emblemático onde auto-imagem real e virtual se fundem e se repulsam. 
O outro trabalhador impõe limites claramente detectáveis quando se trata do discrepante ou do que vem para mostrar a debilidade de toda a organização do trabalho, de todo um modelo do qual o "outro" é depositário e expressão focal. Para não identificar num outro uma desordem, por vezes a tendência é acusar a instituição, símbolo que não se constrange com as escolhas que faz, porque impessoal.

Quando o "outro" é o paciente ou clientela novas percepções são manifestas. Este tipo de "olhar" parece já ter sido mais "educado". O olhar "clínico", herança de uma longa história, não apenas ausculta, deduz, inventaria e designa, mas também esquadrinha, ordena, invade, normatiza e prescreve; "o olhar que vê é um olhar que domina" 6 .

O duplo olhar, "técnico e humano", no confronto com a dor, confessa sua dupla insuficiência. A insuficiência de sua razão instrumental/tecnológica e de seu sentimento de humanidade. A primeira se expressa através das conhecidas queixas contra a falta de condições e recursos - o manejo do atraso e da penúria, "a doença institucional". A segunda se apresenta no silêncio ou no tímido desabafo contra a impotência - o manejo do infortúnio alheio, "a doença social".

Indignar-se e queixar-se nos corredores e salas lotadas, compadecer-se e enternecer-se nos pequenos, reservados e discretos espaços de intimidade: esta parece ser a regra da exposição permitida pela lógica da exclusão e dicotomia entre sentimento $X$ razão, subjetividade $X$ objetividade. Apesar disso, sinais de uma resistência do sentimento estão sempre presentes e solapam, por vezes, a atitude ocidental moderna, fundada no princípio masculino, de enfrentar a dor e o sofrimento atacando-o, suportando-o, nem tampouco penalizando-se com e por ele.

\section{AS BRECHAS DO SER E DO FAZER}

O que o trabalhador faz ao se defrontar com certas impossibilidades e conflitos entre "o seu jeito" e o jeito que "pode" ou "deve" fazer? Como ele responde ao desafio ético-estético de tornar o trabalho uma experiência de auto-expressão? Que espaços de auto expressão, que brechas de resistência da individualidade são reconhecidas e elaboradas?

A partir da fala de trabalhadores e de algumas observações do próprio trabalho pode-se peceber algumas formas de responder a este desafio, caracterizadas principalmemte como respostas ativo-racionais, respostas ativo-emocionais e respostas introspectivas de autopreservação. 
O primeiro tipo de respostas foi o mais freqüentemente relatado e observado: fazer, agir, "não deixar a peteca cair" são expressões chaves. Aqui, fazer o que se acha correto, ao menos parcialmente, é o que dá ao trabalhador a certeza que o justifique a si mesmo e para quem mais quer que seja - "eu me mostro pelo que faço". "Enquanto posso fazer mantenho minha identidade de trabalhador".

No segundo tipo de respostas, o sujeito parece quebrar a hegemonia da razão e dar vazão aos sentimentos envolvidos na situação desafiadora. O sentimento é a forma de expressão que sobressai, ou porque a contenção racional falhou ou porque se estabeleceu de modo não tirânico. É expressão ativa não porque necessariamente venha a culminar em atitudes/ações que provoquem mudanças ou efeitos concretos, mas porque mobiliza energias e pulsões antes contidas - "eu me mostro pelo que sinto". "Enquanto posso sentir e não calar o que sinto sei que ainda sou eu mesmo."

O terceiro modo de responder ao desafio ético-estético do trabalho parece combinar conteúdos da razão e do sentimento de um modo mais equilibrado ou neutro, o que pode sugerir uma certa apatia ou indiferença. $O$ sujeito percebe-se como um elemento de toda aquela realidade vivenciada; um elemento especial, que precisa ser preservado, cuidado, respeitado em suas limitações e necessidades. $O$ trabalhador pensa e sente mas não entra numa torrente de emoções, "stress", esforços e ações compensatórias. Consegue um relativo afastamento e, ao invés de consumir energia (mental ou afetiva), vai guardar ou buscar novas energias, revitalizando-se ou poupando-se. Não se expressa, assim, por ações ou emoções, mas por um certo sentido de autoconsciência e autopreservação - "eu me mostro pelo que sou". Isto significa uma sensibilidade mais genericamente humana e reconciliada consigo mesma.

\section{ÀS BORDAS DO TEMPO}

A importância da percepção do tempo e da relação tempo e sujeito no trabalho em saúde se mostra às bordas do tempo, não porque o trabalhador não esteja corporalmente embrenhado num tempo social com o poder simbólico de construir realidade mas porque escorrega do núcleo deste sistema simbólico e ocupa suas bordas, onde, sem lhe ignorar, exercita um poder de simbolizar, também, seu tempo. Tempo produzido às bordas de um outro tempo. $\mathrm{O}$ "meu tempo", o "tempo do outro" e o "tempo do mundo" coexistem, também no trabalho, e serão estes tempos e suas interrelações que irão dar "a cara das horas" para cada um. A percepção e resposta aos ritmos do cotidiano é mobilizadora e leva o trabalhador à adaptação de seu ritmo a um ritmo e tempo comum. 


\section{A qualidade das horas e o uso do tempo}

A relação peculiar dos trabalhadores com uma ordenação temporal de suas atividades e com um modo bem pessoal de gerir seu tempo, de se movimentar nele e a ele emprestar matizes e qualidades diversos, produz certas regras de uso do tempo e empresta certas qualidades às horas.

Mas, o tempo, mesmo sendo negado em sua possibilidade de criação pessoal e perdido na marcação do fazer rotinizado, recria na vivência de cada trabalhador, no momento solitário e, principalmente, na relação com o sujeito cuidado, as sutis aberturas para uma nova e significativa experiência do tempo. Invertendo-Ihe as regras do uso, tirando-lhe algo aparentemente inexistente, dando-Ihe um curso diverso, roubando-lhe os ponteiros de marcação, o sujeito transforma, mesmo que minimamente, a relação com o tempo que se faz peculiar no trabalho.

\section{DEPOIS DE TUDO... O ATREVIMENTO DE DESEJAR}

Construir uma ponte entre um estudo delimitado e todo um grande espaço aberto à novos questionamentos é estabelecer uma ponte entre o que se mostra e o que ainda não existe, exceto enquanto desejo e projeto. É, assim, uma ponte que se dirige para as margens de um espaço tão ou mais reprimido e sucateado quanto o espaço do real: o terreno do desejo e do sonho.

As falas dos trabalhadores apresentam o contorno por eles dado ao sonho do trabalho ou o "trabalho dos sonhos", quando se constata o modo como o ideal do trabalho vai sofrendo uma nivelização por baixo, como num "cair na real" que faz com que o sujeito desista da singularidade e autenticidade de seu desejo por um tipo de "remendo de sonho".

É no "front do desejo", utilizando a expressão de Guattari ${ }^{8}$, que o sujeito sofre a maior de todas as derrotas, a perda do fluxo e investimento intenso do desejo. O "sonho não sonhado" ou um sonho que perdeu suas formas, que se desmanchou num tempo exigente de realismo, empresta do modelo, do instituido, da lógica presente, um perfil, uma forma não tão bela, mas não tão distante do possível. Deste modo, os mitos guiadores invadem o espaço do sonho e se, por um lado, têm o mérito de enunciar pautas de reivindicações e projetos emancipatórios, com efetividade em lutas focais e sociais, por outro lado, não permitem que o desejo migre do "conhecido" para espaços inteiramente inovadores e singulares, num processo de percepção e sensibilidade totalmente diverso.

O reencontro com os próprios sonhos faz relembrar a contradição entre o vivido e o desejado, entre o que se é e o que se deseja ser. Uma melancolia inevitável, mas também uma lembrança vivificadora. A "memória do não vivido" parece tornar possivel pensar mais longe, querer mais, lembrar que é possivel sonhar para além dos limites existentes e, talvez, com mais clareza com eles se defrontar. 
Atrás de um sonho esconde-se um sujeito; o desejo revela um pouco do que se é. Reconstruir o espaço de seus desejos é reafirmar-se, é lembrar o gosto não experimentado da liberdade e da criação, da certeza de ser capaz de fazer o que nunca fez, de saber que não está aqui para tão pouco. E essa redescoberta, apesar de toda a sorte de limites concretos, nunca deixará de ser um momento revolucionário.

\section{FINALIZANDO: VELHAS E NOVAS QUESTÕES}

Os três marcos iniciais, sociológico, filosófico e da saúde, trouxeram questionamentos bem particulares, embora interconexos na constituição do objeto e em seu aprofundamento.

O marco do trabalho em saúde fez ir mais fundo nestas reflexões à medida que apontou não só para a necessidade de estudos como este mas, principalmente, para as peculiaridades, conflitos, representações e mistificações próprias desta área.

De fato, esta pesquisa demonstrou a importância da construção imaginária do trabalhador sobre si e sobre o trabalho e de como esta se faz no terreno onde se conflitam "mitos guiadores" e a concretude do fazer diário. Evidencia-se a urgência em reconhecer o papel da imaginação e do simbólico na compreensão do trabalho em saúde e com isso a necessidade de posturas teórico-metodológicas que resgatem o "olhar perceptivo" e a sensibilidade à análise e reflexão teórico-científica, valorizando todas as maneiras de se mostrar deste trabalho/trabalhador, seja pela fala, forma, ato ou silêncio.

Já o marco filosófico, antes de ser uma referência, foi uma inspiração, uma permissão para se pensar o novo. Enquanto virtualidade, pode-se dizer que isto talvez nunca ocorra, que não seja acontecimento. Aí a filosofia permite "criar" este acontecimento no terreno de um modo particular de pensar e intuir o universo. Neste estudo não se prescindiu dos procedimentos científicos, que também traçaram sobre realidades, fatos, dados "caóticos", comunicando-Ihes referência, unidades, coordenadas. Mas foi sob o plano da filosofia que se deu a permissão para seu esboço também como "composição estética", não só no sentido já mencionado mas no sentido de uma relação e "preocupação consigo mesmo" (trabalhador de saúde).

\section{Tempo, espaço e sujeito}

Depois de tudo, que sujeito se mostrou ao olhar?; que sujeito se compôs e foi composto por este olhar?

Sujeito e olhar se refazem num espaço e tempo que não são somente categorias fisico-matemáticas. O espaço tornou-se lugar, como no sentido 
bachelardiano, é situado, singular, sítio de experiências, colorido por emoções, povoado por lembranças: "é cenário da vida do corpo". E mais do que isso, é espaço tocado, espaço que se decompõe, se diversifica pela mão que com imaginação escolhe, cria, decide, arbitra e, com vontade, reconhece a resistência do mundo; a mão escapa à tirania de um tempo-espaço fixado pelo conceito e não deixa de tocá-los como matéria a ser trabalhada, "uma matéria que, ao mesmo tempo, resiste e cede como carne amante e rebelde" 10 .

Assim, a imaginação ganha materialidade no espaço recriado e no tempo revivido. Assim, a estranheza do mundo do trabalho é superada e a angústia da finitude e do tempo é contornada na realidade do trabalho: a realidade do instante e do corpo que habita um espaço.

Se obra é depoimento ${ }^{9}$, nas grandes e pequenas obras do trabalho em saúde, o tempo e o espaço, também artesanalmente "trans-formado", depõem sobre esses sujeitos, como parte de uma outra obra: o próprio homem que se faz em obra pela mão criadora. E isto tudo, de tão desapercebido e modesto, quase desaparece frente ao semblante social e tecnológico do trabalho - suas determinações objetivas, sua forma na organização histórica da sociedade.

Tempo e espaço que com sua estrutura, ordenação e códigos, assim como os códigos da conduta, da ciência e do trabalho profissional, confirmam a ordem da submissão, mas nunca eliminam totalmente a resistência pelas fendas do desejo e da criação. Nem o mais privado espaço de uma relação profissionalcliente fica imune a uma ordem sujeitora imprescindivel para que o sistema todo funcione, nem o mais normatizado espaço de serviço impede uma resistência de indócil criação, necessária para que o sujeito, mesmo que latentemente, sobreviva.

Nos artifícios e ritos de autoprodução, desenvolvidos num tempo-espaço também artificialmente movimentado, engendram-se docilidade e insurreição, sujeição e resistência, padronizações e singularizações, mesmo quando a face exposta do trabalho limitado e limitante encubra a face do trabalhador criativo que quer se projetar como realidade possivel.

No sentido de contrapor-se à arbitrariedade do trabalho pela compreensão de um espaço de liberdade possível ou de um novo olhar sobre si mesmo, é que se buscou um entendimento da relação estética deste trabalhador com seu trabalho. Neste trajeto, além do perigo de cair num subjetivismo, enfrentou-se a dúvida e risco apontados por Foucault 5: "em que medida pensar sua própria história pode liberar o pensamento daquilo que ele pensa silenciosamente, e permitir-lhe pensar diferentemente". Talvez por tudo isso, ao final volte-se ao princípio, ao desejo de esboçar o semblante do trabalhador da saúde diferentemente do semblante sempre visto: 


\begin{abstract}
"De que valeria a obstinação do saber se ele assegurasse apenas aquisição dos conhecimentos e não, de certa maneira, e tanto quanto possível, o descaminho daquele que conhece? Existem momentos na vida onde a questão de saber se pode pensar diferentemente do que se pensa, e perceber diferentemente do que se vế, é indispensácel para continuar a olhar ou a refletir".
\end{abstract}

Esta pesquisa revelou que a obra estética da preocupação consigo mesmo não se realiza num esforço crítico de interrogação sobre si tão radical quanto o desejável, ou o suficiente para uma catarse ética que fizesse desfazer-se dos códigos como prescrição para instaurá-los como fruto da procura de si. Mesmo assim, não esconde o desejo de responder à necessidade de abrir as zonas incomunicáveis entre o trabalho/obra e si mesmo, entre uma normatividade dada e seus próprios valores.

Finalmente, pode-se dizer que este estudo coloca-se como idéia regulativa, ou seja, como pensamento que vislumbra e indica uma outra possibilidade; que quer encontrar no real uma outra forma de pensar sobre ele mesmo e, portanto, dar os primeiros sinais no sentido da construção de um caminho possível no plano da reflexão. Nesta perspectiva ele pode se dar a permissão de privilegiar certas dimensões, mesmo que não negue outras já evidentes. Ao ressaltar a transgressão não quer afirmar que toda transgressão é feliz. Ao reclamar pela resistência da individualidade não quer dizer da preocupação exclusiva consigo mesmo, mas do indivíduo que se reconhece na relação com o outro e com os problemas de sua época ${ }^{13}$. Enfim, ao falar de uma expressão estética no trabalho não quer tornar este a única via, ou a mais fácil, de enunciação do sujeito. Ao contrário, reconhece que sempre na história do trabalhador foi a fuga da fadiga e dos infortúnios do trabalho para "ganhar a noite de seus desejos" ${ }^{11}$, e na hora do repouso se encontrar com a música, a letra e as cores, o único caminho de auto-expressão e edificação de algo glorioso e belo em suas existências. Mas este amargo reconhecimento não desiste de uma esperança em responder à maior das tristezas, porque é pensada, a de que as paixões são grandes demais para o espaço que o mundo lhes destina.

Mais do que tudo, e ai reside a poesia deste estudo - na estetização da existência pela via do trabalho, em colocar em primeiro plano a obra de si mesmo implicada na obra social e na crítica de si e da sociedade, portanto nem demasiadamente ingênua ou subjetivista, convencer-se desta possibilidade é uma questão de sobrevivência. 


\section{REFERÊNCIAS BIBLIOGRÁFICAS}

1. BAUDRILLARD, Jean. Da sedução. Campinas: Papirus, 1991.

2. CAPONI, S.N. Do trabalhador indisciplinado ao homem prescindivel. Campinas: UNICAMP, 1992, 301p. Tese (Doutorado em Lógica e Filosofia da Ciência) - Instituto de Filosofia e Ciências Humanas, Universidade Estadual de Campinas, 1992.

3. CASTORIADIS, Cornelius. A instituição imaginária da sociedade. 3.ed. Rio de Janeiro: Paz e Terra, 1991.

4. FELíCIO, Vera L.G. A imaginação simbólica. São Paulo: EDUSP, 1994.

5. FERREIRA, José M. Carvalho. As novas tecnologias, o trabalho e os desafios do sindicalismo. Rev. Plural, Florianópolis, v. 2, n. 3, p.5-11, jul/dez., 1992.

6. FOUCAULT, Michel. História da sexualidade - 2. o uso dos prazeres. 7. ed. Rio de Janeiro: Graal, 1994.

7. O nascimento da clínica. 4. ed. Rio de Janeiro: Forense Universitária, 1994.

8. GUATTARI, Felix; ROLNIK, Sueli. Micropolítica: cartografias do desejo. Petrópolis: Vozes, 1986.

9. OSTROWER, Fayga. A construção do olhar. In: NOVAES, Adauto. O olhar. São Paulo: Companhia das Letras, 1988.

10. PESSANHA, José A. Motta. Bachelard e monet: $O$ olho e a mão. In: NOVAES, Adauto (org.) O olhar. São Paulo: Companhia das Letras, 1988.

11. RANCIĖRE, Jaques. A noite dos proletários: arquivos do sonho operário. São Paulo: Companhia das Letras, 1988.

12. ROSSET, Clement. O real e seu duplo. Porto Alegre: L\&PM, 1988. 
13. SCHMID, Wilhelm. De l'éthique comme esthétique de l'existence. Magazine Litteráire, Paris, n. 309, abr. 1993.

14. SCHRAIBER, L. B.; PEDUDUZZI, M. Tendências e possibilidades da investigação de recursos humanos em saúde no Brasil. Rev. Educ. Med. Salud, v. 27, n.3, p.295-313, 1993.

15. VILLELA PEREIRA, M. Estética, cotidiano e poder. In: I Seminário Internacional de Interdisciplinaridade, 1993, Santa Maria. PROGRAMA ... Santa Maria: 1993. (Discurso proferido em mesa redonda). 